\title{
Operational gas turbine swirl combustors design map for pure methane and different outlet configurations
}

\author{
Mohammed Hamza Abdulsada \\ Departement of Mechanical Engineering, College of Engineerong, University of AL-Qadisiyah
}

\begin{abstract}
The most crucial phenomenon limiting gas turbine burner operation is the flashback and blowoff of flame in the combustor during gas turbine operation. In order to avoid this undesirable phenomenon, it is necessary to predict the operational map area of the gas turbine burner.

Pure methane has been taken as fuel in this analysis, which attempts to construct a design map with two swirl numbers, 1.2 and 1.5. Different configurations for the outlet of the burner ranged from open flame with a normal nozzle, to cylindrical and conical confinements.

The operation map area represents the allowance area of the burner when choosing the equivalence ratio and specified total mass flow rate. The results show that the workable area of the burner increases with the cylindrical and conical confinements, but shows no real difference between the two swirl numbers.
\end{abstract}

\begin{tabular}{l}
\hline Keywords: Gas Turbine, Combustion, Swirl Number, Pure Methane \\
Corresponding Author: \\
Mohammed Hamza Abdulsada \\
Departement of Mechanical Engineering, \\
College of Engineerong, University of AL-Qadisiyah, \\
University Road, AL-Qadisiyah Governmnet, AL-Diwaniyah, Iraq \\
Email: mohammed.abdulsada@qu.edu.iq \\
\hline \hline
\end{tabular}

\section{Introduction}

Identifying the turbine operation limit is crucial. This should include calculating and specifying the correlation, which can be useful to predict and extrapolate according to the existing data. Some of these correlations were involved in the CFD codes [1-5], but none of these relations gave a full explanation of combustion limits and the effect of parametric variations.

Premixed combustion leads to low emissions [6-10] and more complicated relationships due to the influence of low fuel composition $[11,12]$.

Additionally, lean premixed (LP) combustion broadly helps to minimise unwanted negative emissions in gas turbines [2, 13-18]. In lean premixed combustion, air and fuel are mixed past the combustion chamber in order to create a fine mix and increase the efficiency of combustion. To achieve LP, a swirl combustor is widely used, nevertheless, fine combustion could lead to an increase in the propensity of instabilities, flashback and blow off [19-21]. Flashback and blow off are more likely to appear in premixed combustion rather than diffused and partially premixed combustion [20, 22-24].

Many geometrical parameters also affect premixed combustion, such as swirl number, confined, or unconfined flame. These factors relate to the types of combustion and fuel content $[17,19,25]$.

Numerous concerns have been raised by operators and developers of gas turbine technology regarding combustor design. These focus on flashback, blow off, instability, and the possibility of fuel interchange [9, $20,26]$.

The high intensity combustion process is normally stabilised by using swirling flows. Generally, this swirling flow technique is rigorously comprehended because of its sophistication. The formation of a toroidal recirculation zone is the main phenomena of swirling flows which helps to improve flame stability. Furthermore, swirling flows produce high rates of entrainment of the air and fuel mixture, mostly near the wall boundaries of CRZ, and this helps to reduce combustion lengths [27]. 
Combustors using swirl techniques are widely known [28-31]. Their main target is to produce an aerodynamic central recirculation zone (CRZ) and reverse flow zones (RFZ). The chemically heated reactants recycled by CRZ and RFZ to the root of the flame and create flame stability and reduce flashback. Also, give extensive range of the blow off limits [32].

The most vital parameter used to describe swirl flows is the swirl number ( $\mathrm{SN})$. This is defined as the amount of rotation imparted to the axial flow [30, 31]:

$$
S N=\frac{G_{\theta}}{G_{\chi} D_{o} / 2}
$$

$$
\begin{aligned}
& \mathrm{G}_{\theta}=\text { Axial Flux of Angular Momentum } \\
& \mathrm{Gx} \\
& \text { Do }
\end{aligned}
$$

Nevertheless, because of the extremely complex nature of the shape of the flow, it is problematic to define the precise investigational swirl number, unless a clear understanding of three-dimensional velocity measurements is obtainable. A useful value of swirl numbers is found from the shape of the burner and is named the geometric swirl number $\left(\mathrm{S}_{\mathrm{g}}\right)$. This measures the inlet conditions and neglects the pressure differences across the flow. For constant density and isothermal conditions, it should be supposed that the swirl number under investigation (generic swirl burner) shown in Figure 1 is:

$$
S_{g}=\frac{\dot{m}_{i} w_{i} r_{e f f}}{\dot{m}_{o} u_{o} r_{o}}
$$

After some simplification:

$$
S_{g}=\frac{\pi\left(r_{o}^{2}-r_{p}^{2}\right)\left(r_{i}-\frac{t}{2}\right)}{(4 \cdot t \cdot h) r_{o}}
$$

Where,

$u$ is the axial velocity $\mathrm{m} / \mathrm{s}$,

$w$ is the tangential velocity $\mathrm{m} / \mathrm{s}$,

$r_{e f f}$ is the effective (actual) radius at the middle of pipe $\mathrm{m}$,

$r_{o}$ is the exit radius of the burner $\mathrm{m}$,

$r_{i}$ is the inlet radius of the burner $\mathrm{m}$,

$r_{p}$ is the radius of the injector $\mathrm{m}$,

$t$ is the section of the flow width between the blades $\mathrm{m}$,

$h$ is the height of flow section $\mathrm{m}$.

This paper inspects the effect of pure methane fuel upon flashback and blow off, and draws the operation map in a generic, compact, premixed swirl burner for two swirl numbers, using three different geometrical configurations.

\section{Experiment setup}

Numerous tests were undertaken to examine and inspect the flashback and blow off limits for a gas fuel. Here, pure methane used as a working gas under atmospheric conditions was the common swirl burner.

The researchers studied the flame stability limits of generic swirl burners at atmospheric conditions (1bar, 293K) at Cardiff University's Gas Turbine Research Centre (GTRC). Two pipes of pure methane fuel gas entered the burner through the tangential inlet and directly delivered both (air and fuel gas) to an external plenum chamber. This was used for mixing to consistently distribute premixed fuel and air mixture to the insert, which produced a spinning flow (Figure 2) into the body of the burner. The main fuel injector (used only as a stabiliser, and not for fuel injection) penetrated through the entire body of the plenum chamber and swirl burner body to the exhaust (Figure 3). The two swirl numbers had the same design shape, which is the extended exhaust nozzle used, and was $\sim 40 \%$ of the exhaust diameter. Hence, there is the possibility of changing the insert in this design. The two swirl numbers achieved in this experiment used these inserts, containing the tangential inlets, 8 in the case of 1.2 and 6 in the case of 1.5. 


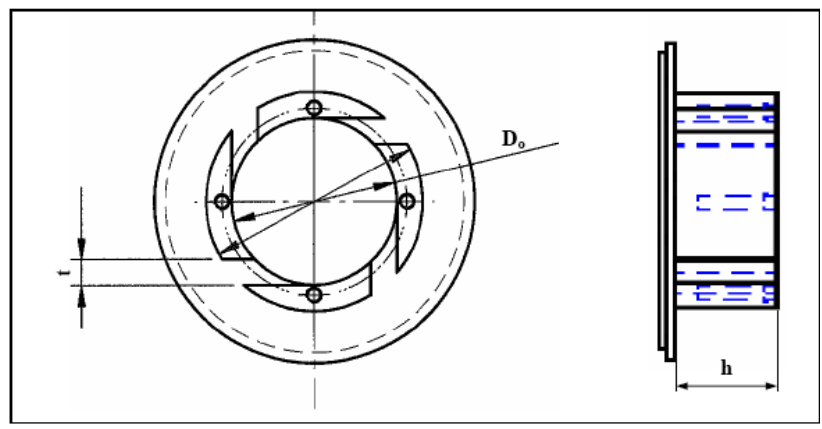

Figure 1. Blade swirler burner shape

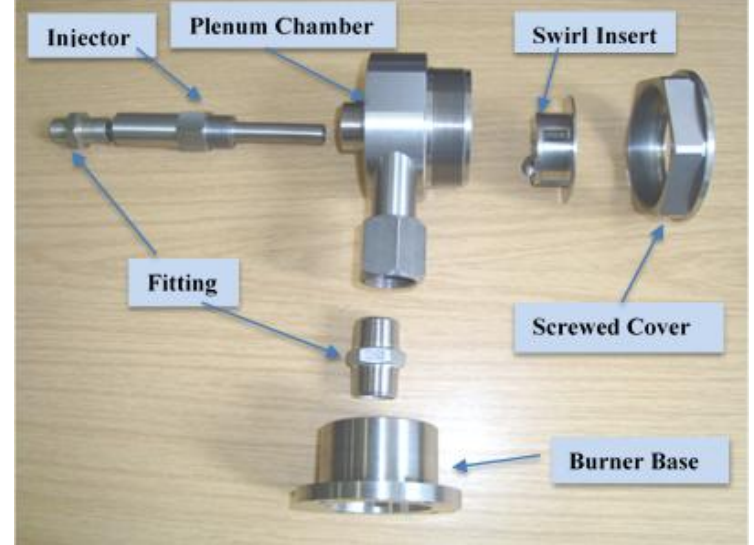

Figure 2. Parts of swirl burner

The central recirculation zone (CRZ) generated by the swirl number was responsible for the stabilisation flame. Additionally, such an arrangement could be accommodated to provide the three combustion modes types of non-premixed, premixed, and partially premixed combustion. The geometry of the burner was improved by adding either cylindrical confinements or a conical cup, as shown in Figure 3.

To measure the mass flow rate of both air and fuel Coriolis meters were adopted for this task, as this gave the best result over other flow meters types, as can be seen in Figure 4.

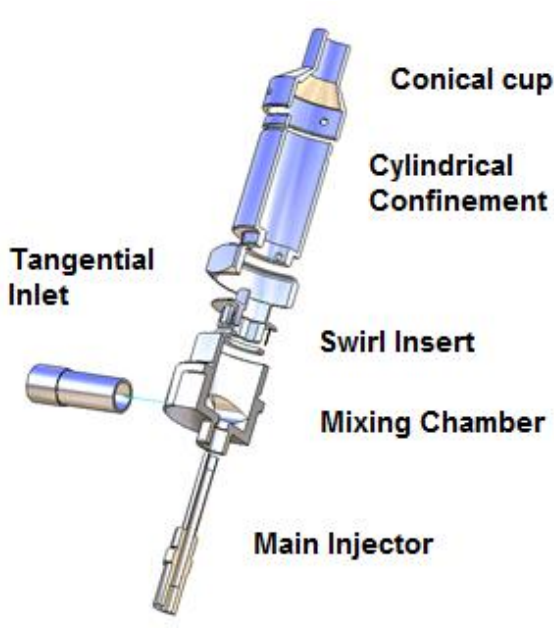

Figure 3. Swirl burner exploded section fitted with cylindrical confinement and conical cup

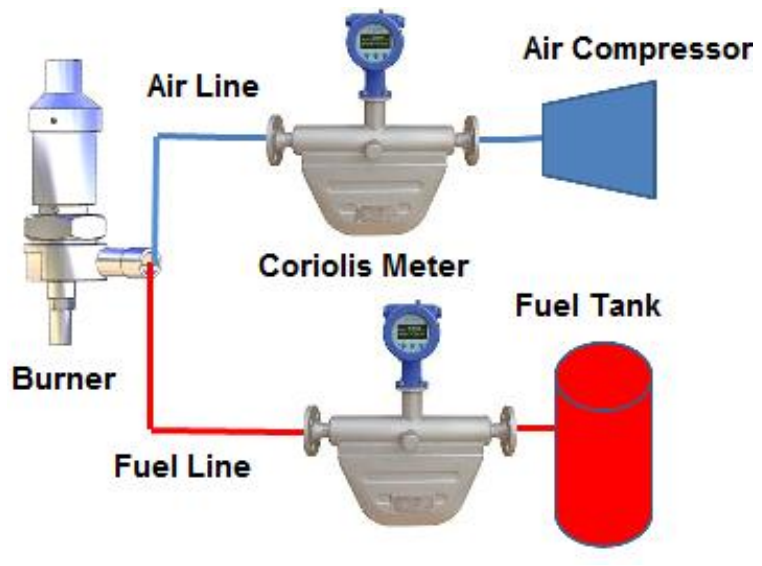

Figure 4. Experimental setup

\section{Results and discussion}

Two swirl numbers with three different outlet configurations and pure methane fuel were tested to examine flashback and blow off results. These experiments were undertaken with the burners ignited into the air environment freely, as well as with cylindrical confinement, and also adding a conical cup.

Figure 5 shows the group of three figures with the relationship between the equivalence ratio $(\varnothing)$ versus the total mass flow rate $(\dot{m})$ for swirl numbers $\mathrm{SN}=1.2$. Each figure reveals the two curves drawn in the same graph showing flashback and blow off, and the area between them represents the operational design area for the combustor. Moreover, Figure 5.A shows open flame without any confinement. The range of area can be useful as the burner became very narrow when it reached equivalence ratio 0.5 and wider as it reached 1 . Thus, it was safe to work at equivalence ratio 1.1 for these examples. Adding cylindrical confinement improved and increased the area of operation and made the wider area an equivalence ratio of less than 0.8. This allowed the possibility of working safely with lean premixed, as can be shown clearly in Figure 5.B. The improvements done through the cylindrical confinements preserved the central recirculation zone (CRZ) for a longer distance than open flame, and avoided instabilities. Figure 5.C reveals the design map with added conical cup above the cylindrical confinements. 


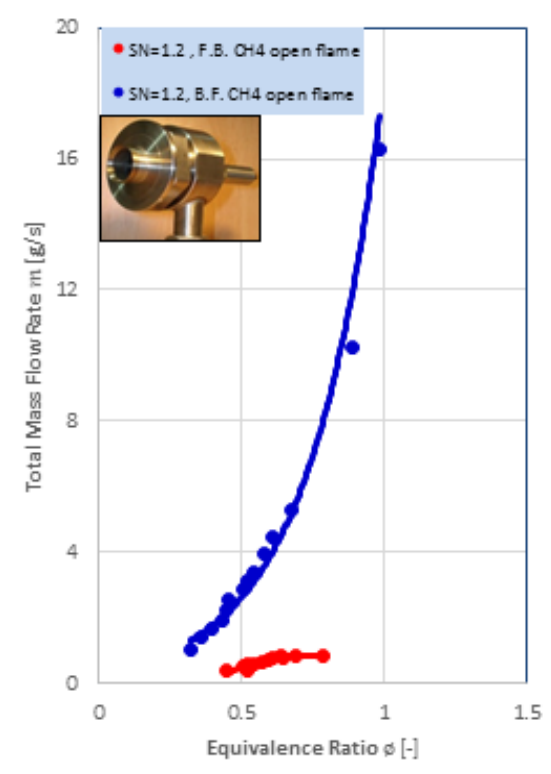

A) Unconfined swirl burner (open flame)

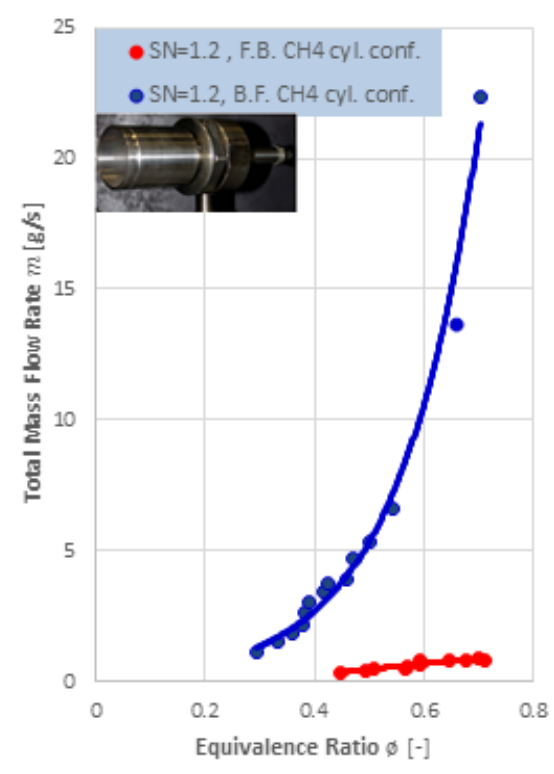

B) Confined swirl burner (cylindrical cylinder)

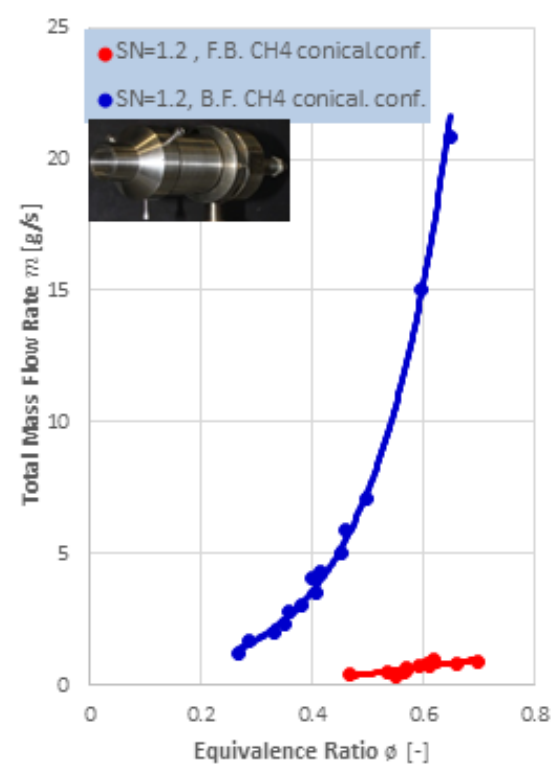

C) Confined swirl burner (conical cup).

Figure 5: Operational Design Map for Swirl Number SN = 1.2 and Pure Methane CH4.

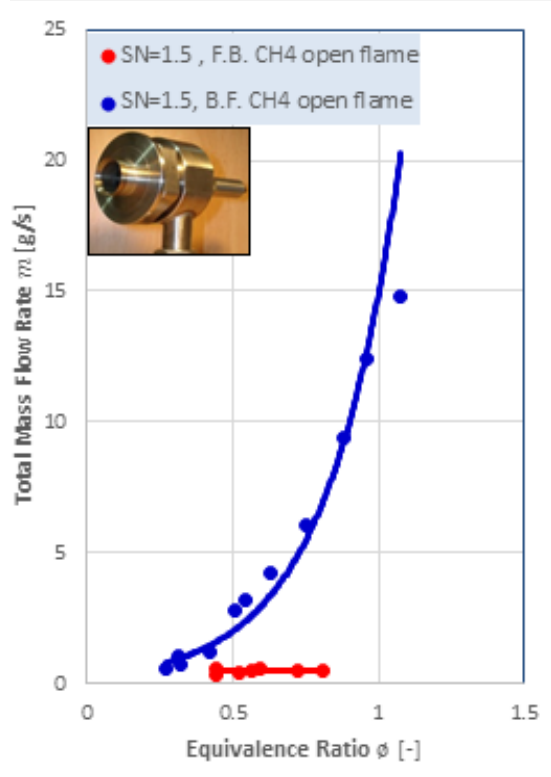

A) Unconfined swirl burner (open flame).

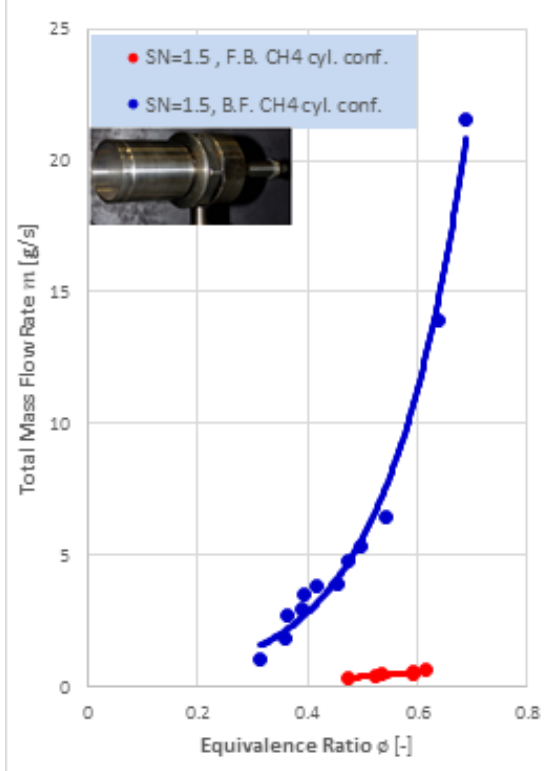

B) Confined swirl burner (cylindrical cylinder).

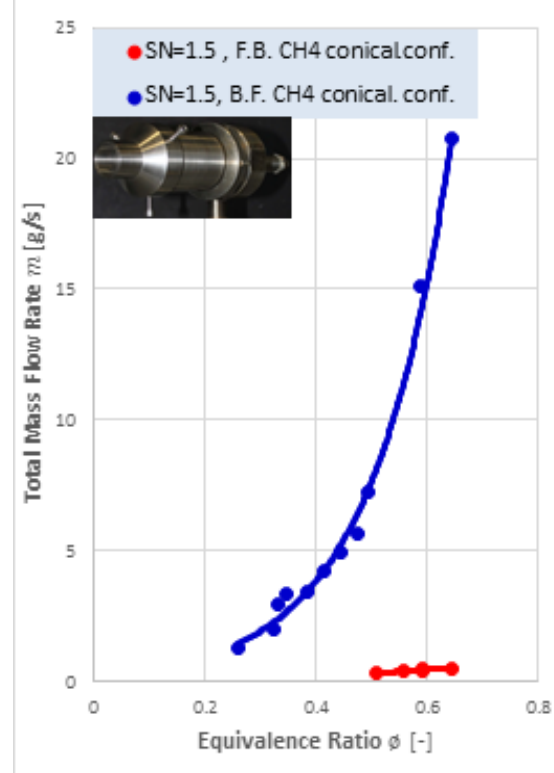

C) Confined swirl burner (conical cup).

Figure 6. Operational design map for swirl number $\mathrm{SN}=1.5$ and pure methane $\mathrm{CH} 4$

The results showed that there was no distinguishing enhancement even giving a wider area between flashback and blow off at a lower value of equivalence ratio. Another group of curves set three graphs of the same as Figure 5. Figure 6 shows the operational area of the burner with swirl number $\mathrm{SN}=1.5$ for more swirl motion. The open flame shows that there was a decrease in the area between flashback and blow off curves in Figure 6.A, even though it gave the same results with both cylindrical confinements and conical cup, as shown in Figure 6.B and 6.C. As can be seen, there were no noticeable differences. 


\section{Conclusion}

Investigation into blow off and flashback phenomena was undertaken with two dissimilar swirl numbers (1.2 and 1.5), and with pure methane as a fuel for three different outlet geometry configurations.

Swirl numbers above 1 gave more swirl and enhance fuel-air mixing. However, this increased the propensity of flashback and blow off, and these factors were decisively influenced by the geometry of the burner.

The operational burner area was increased by adding cylindrical confinements or a conical cup, and this led to the possibility of the burner working with the lean mixture as compared to a burner without confinements. This can be explained by the fact that the confinement reduces vortex breakdown and keeps the central recirculation zone (CRZ), which helps the flame to remain stabilised.

The experiments also show that there was no considerable change in results when adding conical cup above the cylindrical confinement.

Increasing the swirl number from 1.2 to 1.5 had no substantial effect and gave approximately the same operational area, albeit smaller than the later one. However, this increases the possibility of flashback, as it could break the CRZ.

The flashback mechanism appeared to be unlike $\mathrm{SN}=1.5$ as the CRZ overextended back over the injector of pure methane to the base plate. The phenomena of flame also retreated, which is flashback caused by circular movement of the flame front starting from the CRZ boundary and ending at the tangential inlets. In reverse, at smaller value of swirl numbers, for example 1.2 (and with a different exhaust outlet), the flashback mechanism seemed to be through the external wall boundary layer and the critical boundary velocity gradients.

\section{References}

[1] Rago, G.D., et al., CFD analysis of a swirl stabilized coal combustion burner. Energy Procedia, 2018. 148: p. 703-711.

[2] Andreini, A., et al., CFD Analysis of NOx Emissions of a Natural Gas Lean Premixed Burner for Heavy Duty Gas Turbine. Energy Procedia, 2015. 81: p. 967-976.

[3] Mayr, B., et al., CFD modelling and performance increase of a pusher type reheating furnace using oxy-fuel burners. Energy Procedia, 2017. 120: p. 462-468.

[4] Iancu, P., et al., Computational Fluid Dynamics (CFD) Simulation of Fuel Gas and Steam Mixtures to Decrease NOx Emissions of Industrial Burners, in Computer Aided Chemical Engineering, A. Espuña, M. Graells, and L. Puigjaner, Editors. 2017, Elsevier. p. 565-570.

[5] Cappelletti, A., et al., Numerical Redesign of 100kw MGT Combustor for 100\% H2 fueling. Energy Procedia, 2014. 45: p. 1412-1421.

[6] Pandit, J.K., et al., CO2 emission reduction from natural gas power stations using a precipitating solvent absorption process. International Journal of Greenhouse Gas Control, 2014. 28: p. 234-247.

[7] Jones, R.E., Gas turbine engine emissions-Problems, progress and future. Progress in Energy and Combustion Science, 1978. 4(2): p. 73-113.

[8] Mellor, A.M., Gas turbine engine pollution. Progress in Energy and Combustion Science, 1976. 1(2): p. 111-133.

[9] Meratizaman, M., et al., High efficient-low emission power production from low BTU gas extracted from heavy fuel oil gasification, introduction of IGCC-SOFC process. Journal of Natural Gas Science and Engineering, 2015. 23: p. 1-15.

[10] Vatcha, S.R., Low-emission gas turbines using catalytic combustion. Energy Conversion and Management, 1997. 38(10): p. 1327-1334.

[11] Wicksall, D.M., et al. Fuel composition effects on the velocity field in a lean premixed swirlstabilized combustor. 2003.

[12] Noble, D.R., et al., Syngas Mixture Composition Effects Upon Flashback and Blowout. ASME Conference Proceedings, 2006. 2006(42363): p. 357-368.

[13] Huang, Y. and V. Yang, Bifurcation of flame structure in a lean-premixed swirl-stabilized combustor: transition from stable to unstable flame. Combustion and Flame, 2004. 136(3): p. 383389.

[14] Plee, S.L. and A.M. Mellor, Characteristic time correlation for lean blowoff of bluff-body-stabilized flames. Combustion and Flame, 1979. 35(0): p. 61-80. 
[15] Cohé, C., et al., CO2 addition and pressure effects on laminar and turbulent lean premixed CH4 air flames. Proceedings of the Combustion Institute, 2009. 32(2): p. 1803-1810.

[16] Schefer, R.W., D.M. Wicksall, and A.K. Agrawal. Combustion of hydrogen-enriched methane in a lean premixed swirl-stabilized burner. 2002.

[17] Abdulsada, M., et al., Effect of exhaust confinement and fuel type upon the blowoff limits and fuel switching ability of swirl combustors. Applied Thermal Engineering, 2012. 48: p. 426-435.

[18] Huang, Y. and V. Yang, Effect of swirl on combustion dynamics in a lean-premixed swirl-stabilized combustor. Proceedings of the Combustion Institute, 2005. 30(2): p. 1775-1782.

[19] Abdulsada, M., et al., Effect of Swirl Number and Fuel Type upon the Blowoff Limits in Unconfined and Confined Swirl Combustors, in PRO-TEM, TATA Conference Meeting. 25th-26th October, 2011: Newcastle, UK.

[20] Syred, N., et al., The effect of hydrogen containing fuel blends upon flashback in swirl burners. Applied Energy, 2012. 89(1): p. 106-110.

[21] Syred, N., et al., Effect of inlet and outlet configurations on blow-off and flashback with premixed combustion for methane and a high hydrogen content fuel in a generic swirl burner. Applied Energy, 2014. 116: p. 288-296.

[22] Syred, N., et al., The effect of hydrogen containing fuel blends upon flashback in swirl burners, in PRO-TEM, TATA Conference Meeting. 2010: Newcastle, UK.

[23] Abdulsada, M., et al., Effect of swirl number and fuel type upon the flashback in swirl combustors, in AIAA conference paper. 4-7 January 2011: Orlando, Florida, AIAA 2011- 889442.

[24] Shelil, N., et al., Premixed Swirl Combustion and Flashback Analysis with Hydrogen /Methane Mixture in 48th AIAA Aerospace Sciences Meeting. Orlando, USA, ref. AIAA-2010-1169, 2010.

[25] Zhang, T.-H., F.-G. Liu, and X.-Y. You, Optimization of gas mixing system of premixed burner based on CFD analysis. Energy Conversion and Management, 2014. 85: p. 131-139.

[26] Haugen, N.E.L., C. Brunhuber, and M. Bysveen, Hydrogen fuel supply system and re-heat gas turbine combustion. Energy Procedia, 2012. 23: p. 151-160.

[27] Syred, N. and J.M. Beér, Combustion in swirling flows: A review. Combustion and Flame, 1974. 23(2): p. 143-201.

[28] Syred, N., Generation and Alleviation of Combustion Instabilities in Swirling Flow, in Advanced Combustion and Aerothermal Technologies, N. Syred, and A. Khalatov. 2007, Springer. p. 3-20.

[29] Syred, N., N.A. Chigier, and J.M. Beér, Flame stabilization in recirculation zones of jets with swirl. Symposium (International) on Combustion, 1971. 13(1): p. 617-624.

[30] Syred, N., A.K. Gupta, and D.J. Lilley, Swirl Flows 1984, Tunbridge Wells, United Kingdom.: Abacus Press.

[31] Lefebvre, A.H., Gas Turbine Combustion. 2 ed. 1999, New York: Taylor \& Francis Group.

[32] Nicholas, S., A review of oscillation mechanisms and the role of the precessing vortex core $(P V C)$ in swirl combustion systems. Progress in Energy and Combustion Science, 2006. 32(2): p. 93-161. 